UDC: $811.134 .2: 811.163 .41]: 398$

DOI: https://doi.org/10.18485/hispserb.2019.2.ch7

\author{
Ivana Georgijev ${ }^{\mathbf{1}}$ \\ Universidad de Novi Sad \\ Serbia
}

\title{
LA MUERTE COMO UN FENÓMENO METAFÍSICO EN LAS PAREMIAS SERBIAS Y ESPAÑOLAS: ENFOQUE ETNOLINGÜÍSTICO
}

\begin{abstract}
Resumen
El fenómeno de la muerte, como parte inseparable de la vida, no deja de llamar la atención desde los tiempos más remotos de la humanidad. Por esta razón, supone una cuestión ineludible en la investigación antropológica, etnológica y cultural. Debido a su universalidad, ha sido seleccionado como tema de este trabajo, el cual abordamos desde la perspectiva de la etnolingüística, analizando las paremias serbias y españolas. Es bien sabido que las paremias contienen mucha información sobre las características sociales, históricas y culturales de la comunidad que las utiliza, y por lo tanto representan un verdadero tesoro lingüístico y cultural. El tema de la muerte, debido a su universalidad y presencia en la vida de las personas, ha encontrado su lugar en las paremiologías serbia y española, como demuestran numerosos refranes. El corpus, recopilado a partir de diversas fuentes de español y serbio, representa una parte importante de las culturas orales y del folclore serbio y español, que describe las creencias de las dos sociedades, principalmente en el nivel colectivo de actitudes y reflexiones sobre este tema. El objetivo es señalar las similitudes y diferencias entre estas dos sociedades y culturas, con el fin de confirmar el alcance cultural y etnolingüístico de las paremias, así como la importancia de su estudio comparativo.
\end{abstract}

Palabras clave: etnolingüística, paremia, muerte, serbio, español.

${ }^{1}$ ivana.georgijev@ff.uns.ac.rs 


\section{Introducción}

El fenómeno de la muerte, como parte inseparable de la vida, no deja de llamar la atención desde los tiempos más remotos de la existencia humana. Algunas sociedades han adorado a la muerte mientras que otras han adorado a la vida. Asimismo, el significado de la muerte es una cuestión de definición cultural (Kearl 1989: 58). Debido a que el concepto de la muerte está afectado por la cultura, se considera que las ideas, las creencias y las costumbres relacionadas con la muerte pueden variar de una cultura a otra. Cada comunidad construye creencias, mitos y rituales relacionados con este fenómeno de acuerdo con sus características históricas, religiosas y culturales, por lo que es necesario prestar especial atención a las influencias de la religión popular, el paganismo, la mitología y el cristianismo en las percepciones de la muerte. Debido a su universalidad, el fenómeno de la muerte ha sido elegido como tema de este trabajo.

Este estudio presenta un análisis de los refranes serbios y españoles referentes al concepto de la muerte como un fenómeno metafísico. El objetivo del trabajo es identificar las diferentes interpretaciones de la muerte en las sociedades y culturas serbia y española. Partimos de la idea de que las paremias ${ }^{2}$ de una comunidad expresan sus visiones del mundo. Estamos interesados en las similitudes y diferencias en la percepción de la muerte en los dos idiomas e intentaremos identificar las bases culturales (religiosas, sociales, etc.) de las dos comunidades lingüísticas. En particular prestaremos atención a la importancia que ha tenido la religión cristiana en la formación del significado de la muerte y la comprensión de este fenómeno en estas dos comunidades. Teniendo en cuenta que la respuesta a la pregunta ¿qué consecuencias tiene la conceptualización de la muerte en las prácticas cotidianas del hombre? ya se ha dado (Georgijev 2018b), el enfoque de este trabajo es investigar qué es la muerte en el sentido metafísico. De acuerdo con lo anterior, la pregunta que trataremos de responder es: ¿Cómo los miembros de las comunidades serbia y española entienden y conceptualizan la muerte, es decir, qué tipo de percepciones de la muerte existen en la conciencia de los miembros de estos dos pueblos?

Cabe destacar que las lenguas serbia y española (una eslava y la otra románica) poseen ciertas diferencias lingüísticas pero al mismo tiempo comparten ciertas características (fonéticas, morfológicas,

\footnotetext{
${ }^{2}$ En este trabajo, el término paremia se usa como sinónimo de refrán o dicho.
} 
sintácticas o léxicas) ya que pertenecen a la familia de las lenguas indoeuropeas. Igualmente, comparten el contexto geográfico y cultural europeo así como la tradición religiosa (cristiana). Por lo tanto, podemos suponer que los miembros de estas dos comunidades también comparten ciertas visiones del mundo. Las paremias han sido seleccionadas para su análisis debido a que reflejan el contexto socio-histórico y el rico patrimonio cultural de la comunidad que las usa. Entendidos como ejemplos de sabiduría popular de una comunidad, los refranes referentes al concepto de muerte se analizan con el fin de ver qué rasgos culturales manifiestan y qué valores expresan en cada una de las lenguas y culturas. Investigaciones similares sobre este tema en las lenguas y culturas serbia y española están en desarrollo. ${ }^{3}$ Por lo tanto, la intención que tenemos es contribuir con esta investigación al campo de la paremiología, pero también al ámbito de la cultura y la religión, que inevitablemente han dejado huella en las paremias de estas dos comunidades. Teniendo en cuenta que la etnolingüística es una disciplina que estudia las relaciones entre el idioma y la cultura de uno o varios pueblos, es decir, la conexión entre el idioma, la cultura y la etnia, con este trabajo queremos contribuir a la investigación comparativa de los dos idiomas y de las dos culturas.

\section{La etnolingüística y la paremiología: el refrán como un producto cultural}

$\mathrm{Al}$ servir como instrumento para categorizar y conceptualizar la realidad, la lengua contribuye a su comprensión y a su interpretación, así como a la elaboración de un modelo cultural y a la interiorización del mismo (Buxó 1983 apud Pascual López 2014: 171). La lengua es producto de la cultura pero también es una fuerza que la configura. En este sentido, la lengua tiene un papel importante en la transmisión y la perpetuación de la cultura o de la visión relativa de la realidad con que cada comunidad lingüístico-cultural se enfrenta al mundo. Esto es resultado de la interiorización de patrones o modelos culturales que, pese a ser subjetivos, aparecen en la mente como objetivos e innatos, como

\footnotetext{
${ }^{3}$ En cuanto a la investigación comparativa sobre el tema de la muerte en las paremias serbias y españolas, ya se ha mencionado el trabajo que trata el tema de la conceptualización de la muerte en las prácticas cotidianas del hombre (Georgijev, 2018b). El mismo tema se aborda desde la perspectiva de la lingüística cognitiva a través del análisis de las metáforas españolas y serbias en Georgijev (2018a) así como desde la perspectiva cognitivoantropológica y la teoría de los modelos culturales cognitivos en Georgijev (2015), trabajo sobre la muerte como tabú en las culturas serbia y española.
} 
fruto de una experiencia que no se pone en duda (Pascual López 2014: 171). La etnolingüística, base teórica de este trabajo, es "la disciplina que estudia las relaciones entre la lengua y la cultura de uno o varios pueblos" (RAE). Esta disciplina, en términos generales, estudia tanto la variación de la lengua en relación con la cultura como los aspectos de los usos lingüísticos relacionados con la identidad étnica, tratando al mismo tiempo de descubrir las diferencias entre culturas.

Se conoce también como lingüística antropológica y antropología lingüística. Estos términos se utilizaron en el pasado de forma más o menos intercambiable. En la comunidad académica y científica contemporánea estos términos a menudo se entienden como sinónimos: la denominación de la antropología lingüística alterna con la de lingüística antropológica en la tradición estadounidense, mientras que en Europa domina el término de etnolingüística (Duranti 1997: 1-2; Duranti 2009: 2). El estudio de la relación entre el lenguaje, el pensamiento y la cultura, es una rama tanto de la antropología como de la lingüística (Danesi 2004: ix). Uno de los temas sobre los que opera la etnolingüística es el análisis de los refranes como manifestación de la cultura popular. ¿Por qué es así? Los refranes son frases que expresan verdades intemporales aceptadas por una sociedad o comunidad, adquiridas durante mucho tiempo y transmitidas de generación en generación. Representan una fuente fértil del patrimonio etnolingüístico puesto que el corpus paremiológico puede entenderse como un depósito de cuantiosa información sobre la idiosincrasia de una determinada comunidad lingüístico-cultural (Pascual López 2014: 173). Son un verdadero tesoro lingüístico y cultural, y retratan de manera concisa y gráfica imágenes y eventos del pasado, en los que se basa nuestro presente y en los que reside nuestro futuro. Cada comunidad genera sus propios refranes, adaptados a circunstancias específicas, geográficas, sociales o de otro tipo (Pejović 2014: 201-202). También nos facilitan la reconstrucción del pensamiento, las costumbres y la organización social de una cierta comunidad, puesto que constituyen "un microcosmos cultural en el que varios códigos específicos se encuentran implicados" (Forgas 1992: 296 apud Pascual López 2014: 173). Esta naturaleza de los refranes valida su análisis desde el enfoque interdisciplinar de la etnolingüística, que, a grandes rasgos, pretende demostrar "el valor de la lengua para reflejar, reproducir, conservar y transmitir la cultura de un pueblo" (Forgas 1993: 35 apud Pascual López 2014: 173). La etnolingüística aplicada a la paremiología permite rechazar la tradicional concepción de los refranes como perlas emanadas de la sabiduría popular, para entenderlos como productos de una cultura específica poseedora de una cosmo-visión determinada (Pascual López 2014: 176). 


\section{La muerte en la cultura occidental y en el Cristianismo}

La muerte es el mayor misterio de la vida. Es uno de los temas que la gente afronta en todas las partes del mundo, en las sociedades preindustriales tanto como en las industriales, en el pasado tanto como en el presente. Por eso es un tema inevitable en las investigaciones antropológica, etnológica y cultural.

Los humanos no pueden aceptar la transitoriedad total de la vida y comprender la «no-existencia absoluta» de los muertos (Tadić 2003: 232), por lo que el miedo a la muerte y la creencia en la vida después de la muerte son un fenómeno universal (Berta 2003: 13). Como consecuencia, la base de todas las religiones siempre ha sido la necesidad de resolver un mismo problema: ¿Cómo soportar el final de la vida? (Becker 1973 apud Erić 2001: 27). Asimismo, se considera que la religión afronta dos de los miedos humanos básicos: el miedo a la muerte y el miedo a lo que nos sucederá después de morir (Conzelus Moore \& Williamson 2003: 5). La conciencia humana no conoce la respuesta a la pregunta de qué nos espera al otro lado de esta vida, es decir, qué ocurre después del momento de la muerte. Esta pregunta, vista a través de la dimensión histórica, siempre ha estado entrelazada con los sentimientos religiosos (Erić 2001: 88-89). La mortalidad del individuo humano es el elemento fundamental de la religión, mientras que el miedo a la muerte es el sentimiento religioso más poderoso (Krešić 2006: 91).

Platón (427-347 a.C.) sentó las bases para un pensamiento filosófico sobre la muerte característico de la cultura occidental, en particular con la enseñanza de la inmortalidad. Él creía que el alma era inmortal: cuando la muerte se acerca al hombre, deja intacta el alma. Desde el nacimiento y a lo largo de la vida el alma y el cuerpo se ven unidos pero el alma tiene su propia existencia y por eso se libera del cuerpo en el momento de la muerte (Erić 2001: 28-29). La concepción de la inmortalidad de Platón influyó en las principales tradiciones religiosas de Occidente, principalmente en el judaísmo y el cristianismo (Erić 2001: 29). La iglesia incluso ha monopolizado históricamente los sistemas de significado de la muerte y los rituales relacionados con este fenómeno, siendo la institución que nos ha traído las concepciones de la salvación y la resurrección, el cielo y el infierno, el símbolo de la cruz. De todas las instituciones sociales, la iglesia ha tenido el impacto más directo en el lenguaje, la lógica y el espíritu del fenómeno cultural de la muerte (Kearl 1989: 172, 197). Tanto la interpretación católica como la ortodoxa de la muerte se basan en el cristianismo (Boisclair 2010: 56), por lo cual 
podemos suponer que el análisis de las concepciones de la muerte de las comunidades serbia y española mostrará influencias de la religión cristiana y similitudes en sus visones de este fenómeno.

El análisis de las paremias serbias y españolas que tratan el mismo tema a nivel de las prácticas sociales (Georgijev 2018b) muestra el impacto de la conceptualización de la muerte en las prácticas cotidianas del hombre y en la estructuración del comportamiento social. Los resultados indican que la muerte es vista como un fenómeno inevitable aunque en la vida se debe superar el miedo a la muerte. Además, uno debe comer y beber con moderación para tener una vida larga y saludable. Las paremias serbias glorifican el coraje y la disposición para luchar por la libertad, aunque sea a toda costa. Los refranes en ambos idiomas indican la existencia del funeral como un ritual importante mientras que en español encontramos ejemplos en los que llorar y vestirse de negro representan formas de expresar el luto y la pena por la muerte de alguien. Cuando se trata de las virtudes humanas, el honor y la honestidad se consideran muy importantes en ambas culturas. La sabiduría y la prudencia a la hora de hablar también se recomiendan cuando se expresan pensamientos propios y opiniones.

El análisis que presentamos a continuación, por lo tanto, pretende complementar la investigación arriba citada. En este trabajo nos centramos en la muerte como un fenómeno metafísico, entrelazado con la religión cristiana pero también con las tradiciones precristianas.

\section{Análisis}

A continuación analizamos las paremias serbias y españolas, así como las similitudes y diferencias entre ellas. Los refranes seleccionados han sido agrupados en 5 apartados según los temas e ideas que ilustran.

\subsection{Existencia del alma}

Numerosos mitos y especialmente religiones predican - todos a su manera - que la muerte física no significa el final de la vida sino un cambio en su forma, lo que representa el postulado de la inmortalidad. El concepto de la inmortalidad supone que el cuerpo no es una forma verdadera de existencia, sino que es el alma la que simboliza la vida. Mientras que el cuerpo es transitorio, se considera que el alma es duradera e inmortal. Visto de esa manera, se niega la finalidad del ser humano. Ese dualismo del cuerpo y el alma constituye la característica 
principal de muchas religiones. El cuerpo, es decir, toda la existencia terrenal, se desprecia y se ve como algo temporal y efímero, mientras que la existencia inmortal del alma se valora y aprecia porque se relaciona con la eternidad (Tadić 2003: 14, 31-32).

Encontramos los siguientes ejemplos donde se menciona el alma: Bog da mu duši pokoj da! = Bog da mu dušu prosti! (iQue Dios le dé descanso al alma!); El alma a Dios, el cuerpo a la tierra, y la ropa a quien la quiera; (La) muerte de cada alma, escrita está en la palma (cada criatura tiene trazado su destino y no puede modificarlo). El ejemplo Tako mi duša hrišćanska ispala (Que se me caiga el alma cristiana = Que me muera), se usa si queremos asegurar que decimos la verdad.

El cristianismo ha "tomado prestadas" muchas visiones del mundo de las creencias precristianas. Las creencias sobre el alma y la inmortalidad son esencialmente las mismas en las creencias precristianas y en el cristianismo por lo que es obvio que la religión precristiana y cristiana se entrelazaron, se fusionaron y se sincronizaron (Zečević 1982: 100). El culto a los muertos en todas las naciones indoeuropeas en el pasado se basaba en la comprensión animista del mundo (del latín anima - el alma): la muerte se explica con el hecho de que el alma abandona el cuerpo (parte material y tangible); cuando el cuerpo permanece sin alma, es decir, sin vida, eso significa que muere. Según este entendimiento, el alma vive para siempre - es inmaterial (Zečević 2007: 15).

En cuanto a la ubicación del alma, en las creencias serbias no se determina con precisión la apariencia del alma, ni dónde está su residencia permanente. Se considera que el alma se encuentra en algunas partes vitales del cuerpo. Sin embargo, está marcado el camino por el cual el alma abandona el cuerpo: la nariz o la boca (Zečević 2007: 94). El alma sale / abandona el cuerpo junto con el último aliento: por eso se dice todavía hoy que una persona (que acaba de morir) "exhaló" (izdahnuo je) y "soltó el alma" (ispustio dušu); "su alma está en la nariz" (duša mu je u nosu) se dice cuando una persona está mortalmente enferma o está a punto de morir (Zečević 2007: 18, 23). Esta idea la encontramos en una paremia serbia: Duša mu u nosu stoji. / Stoji mu duša u nosu. (Su alma está en la nariz = Está a punto de morir).

\subsection{Juicio final / día del juicio}

La mayoría de las sociedades y religiones antiguas tenían esa idea del juicio posterior a la vida, especialmente entendido como un "pesaje de almas", donde los dioses recompensaban a los fieles creyentes (McGuckin 
2003: 404). El Día del Juicio Final es el día en que los muertos son llamados para ser juzgados, y son recompensados o condenados para siempre por la forma en la que han vivido (Braun 2000: 84). Según la enseñanza cristiana, la vida después de la muerte existe en dos mundos diferentes, en el paraíso y en el infierno. Después de la muerte, los justos continúan viviendo en el paraíso, y los pecadores van al infierno. Muchas otras religiones dualistas tuvieron conceptualizaciones similares: su enseñanza básica es la lucha entre el bien y el mal. El cristianismo ha sintetizado estos conceptos y los ha adaptado a sus necesidades (Zečević 1982: 25). Encontramos varios ejemplos con esta idea: Como se vive, se muere (= De la vida que uno lleve depende el fin que tenga - las costumbres determinan en gran medida el tipo de vida y el probable final de cada uno); Bien muere, quien bien vive. Dos paremias serbias sugieren la existencia del día decisivo que llega y marca la muerte (corporal). "Sudjeni dan" supone el día del juicio: Nema smrti bez suđena dana (No hay muerte sin el día final); Muka dušu ne vadi no suđeni dan (No lleva la pena el alma [al otro mundo] sino el día final).

Asimismo, muchas personas esperan volver a encontrarse con sus seres queridos cuando mueran (Kastenbaum 2003: 458). Se reencuentran, es decir, se unen con sus queridos en la vida que les espera después de la muerte. Primero los espera un encuentro con Dios, lo que vemos en la paremia serbia: Otišao Bogu na istinu. Los que mueren van al cielo porque el paraíso se encuentra arriba, en el cielo: los mitos y las leyendas de la resurrección de Jesús están relacionados con el mito del reino de los cielos al cual, después de la muerte, van los cristianos justos (Vukomanović 1992: 119). El cielo aparece en la paremia en español: Matrimonio y mortaja, del cielo bajan. Este ejemplo señala lo poco que sirven los propósitos humanos cuando se trata del casamiento o de la muerte.

\subsection{La fecha y el lugar de la muerte son inciertos}

El cese de la vida no es un acto voluntario ni está predeterminado. Cuando llega el momento, alguien viene por el alma, la separa del cuerpo y la lleva a otro mundo (Zečević 2007: 21). Sin embargo, la fecha y el lugar de la muerte son inciertos como podemos ver en las siguientes paremias: Muerte cierta, hora incierta; El morir es cierto; el cuándo, el cómo y el dónde, inciertos; Se sabe dónde se nace, pero no dónde se muere; La muerte siempre es traidora: no dice el día ni la hora. 


\subsection{La inevitabilidad de la muerte (existencia del destino)}

La tradición cristiana llama a la muerte "el fin de una peregrinación" o "el fin del viaje de una persona". La vida entera de una persona se ve, en cierto sentido, como una preparación para la muerte. La muerte representa el cese de la responsabilidad de uno para moldear su propia vida terrenal y para alcanzar la salvación a través de la gracia de Dios (Braun 2000: 84). La muerte alcanza a todos: es inevitable. Lo que trae cierto alivio es la existencia del destino, lo que libera a la gente de la responsabilidad. Las paremias serbias dicen: Ko se rodi, onaj će i umrijeti (Quien nace, muere); Niko ne živi dva vijeka / Ne daju dva vijeka nikome (Nadie vive dos vidas / No le dan dos vidas a nadie); U našoj je vlasti kako ćemo živeti, a ne koliko (Está en nuestro poder cómo vivimos pero no cuánto); Niko se smrti nije oteo (Nadie se escapó de la muerte); I ko bježi od smrti, nije utekao (El que huye de la muerte tampoco se escapa); Danas čovek sutra crna zemlja (Hoy un hombre, mañana tierra negra); Jednom se rađa a jednom umire (Se nace una vez y se muere una vez); Mlad može a star mora umrijeti (El mozo puede morir y el viejo debe morir); Od smrti nema skloništa (De la muerte no hay refugio); Dvije smrti ne čekaju, a jedna ne manjka (Dos muertes no esperan pero una no falta); Što dalje, sve bliže smrti (Cuanto más lejos, más cerca de la muerte); Grob je bliži od kuće (La tumba está más cerca que la casa); Ko se rodio za vešala, od puške ne gine (Quien nació para la horca, no muere por la escopeta); Koga Bog čuva, onoga puška ne bije (A quien Dios guarda, no le mata la escopeta). Ya hemos mencionado dos paremias serbias que sugieren la existencia del "día decisivo" que llega y marca la muerte (corporal) y la existencia del destino: Nema smrti bez suđena dana (No hay muerte sin el día final); Muka dušu ne vadi no suđeni dan (No lleva la pena el alma [al otro mundo] sino el día final). "Sudjeni dan", además de suponer el día del juicio (porque "suditi" significa juzgar), puede referirse al día predestinado para la muerte del ser humano y relacionarse con el destino.

Encontramos la misma idea en las paremias españolas: Nadie se muere hasta que Dios quiere; El mozo puede morir, y el viejo no puede vivir; Dentro de cien años, todos calvos / De hoy en cien años, todos seremos calvos (= transcurrido ese tiempo ya habremos muerto y nuestra cabeza se reducirá a una calavera; por tanto, estaremos libres de las miserias de esta vida.); A todo hay remedio, sino a la muerte / Todo tiene remedio menos la muerte (= se emplea a modo de consuelo para quien ha sufrido alguna desgracia o contratiempo.); (La) muerte de cada alma, escrita está en la palma (= cada criatura tiene trazado su destino; a nadie, por 
tanto, le es dado modificarlo); Muerte deseada, vida asegurada (= el que desea la muerte, vive mucho tiempo; el hombre no lo decide); Matrimonio y mortaja, del cielo bajan (= señala lo poco que sirven los propósitos humanos cuando se trata del casamiento o de la muerte.); No hay vida sin muerte, ni placer sin pesar (= alude a la imposibilidad de alcanzar la dicha completa, porque siempre hay algún perjuicio o algún sinsabor.); Muerte cierta, hora incierta. Además, todos son iguales antes de la muerte: La muerte todo lo barre, todo lo iguala y todo lo ataja (= con la muerte, desaparecen todas las diferencias que existen entre los seres humanos.); El pobre y el cardenal, todos van por igual (= todos los seres vivos han de morir sin distinción alguna.); Muérese el rey, y el papa, y el que no tiene capa (= la muerte alcanza a todos); La muerte es juez severo, que a todos mide por un rasero; Tan presto muere el rico como el mendigo.

\subsection{Morir es vivir eternamente}

El hombre no está listo para aceptar la muerte física como un camino "a la nada" y la religión "se alimenta" con esta ansiedad (Kuljić 2014: 15). En el corazón de la fe cristiana se encuentra la creencia en la resurrección de Cristo y la posibilidad de que, a través de la fe en Cristo, la humanidad resucite en la vida eterna. Cuando la muerte es vista como un punto de tránsito hacia la vida eterna, puede ser aceptada con más facilidad (Brown 2000: 84). El consuelo se basa en la esperanza cristiana y en la creencia en la resurrección de los muertos. Esa creencia supone el comienzo de una nueva existencia en el paraíso, ese destino bendito que representa el cumplimiento de la fe cristiana (Wheeler 1994 apud Fernández 2006: 104). Las creencias religiosas siempre han proporcionado un tipo de alivio en relación con la muerte, especialmente el alivio en forma de promesa de vida eterna que sobrepasa o supera a la muerte física y corporal (Fernández 2006: 104). Los refranes muestran que el que muere, si en su vida se ha comportado bien, vivirá eternamente. La creencia en la vida después de la muerte, como un fenómeno religioso, libera a la gente de la conciencia cotidiana de su finalidad y del temor a ese conocimiento (Erić 2001: 88). Lo que supone un objetivo para los creyentes es alcanzar la salvación, es decir, la vida eterna a través de la gracia de Dios. Encontramos las siguientes paremias que manifiestan esta idea: Muere y vivirás. (El que muere, si en su vida se ha comportado bien, vivirá eternamente.); Morir es volver a vivir. ("Vivir" en sentido sobrenatural). La paremia serbia dice que morir es lo mismo que resucitar ya que la resurrección supone la salvación de una vida dura: Zlu životu smrt je vaskrsenje (Para una vida dura la muerte es resurrección). 
La creencia en la inmortalidad y la prolongación de la vida en la eternidad es una de las defensas más complejas contra el miedo, característica de la civilización occidental desde sus inicios hasta la actualidad (Erić 2001: 87). La existencia física y transitoria del hombre termina en el momento de la muerte. Sin embargo, ese momento no se ve como un fin, sino como un nuevo comienzo: la etapa más importante de la existencia humana, lo que supone la vida eterna (Popović 2011: 163).

\section{Conclusiones}

De acuerdo con el objetivo de este trabajo - mostrar las creencias de las comunidades serbia y española a nivel colectivo de actitudes y reflexiones sobre el tema de la muerte - partimos de la pregunta: ¿Qué es la muerte en la conciencia de las comunidades española y serbia a nivel metafísico y qué tipo de influencia en las interpretaciones del fenómeno de la muerte han tenido la religión popular, el paganismo, la mitología y el cristianismo?

En primer lugar, cabe destacar que se ha confirmado la hipótesis general de que las diferencias entre las paremias respecto al tema de la muerte (desde el punto de vista metafísico) no son mayores puesto que manifiestan muchas similitudes en la comprensión del fenómeno de la muerte. Ese resultado se debe mayormente a que Serbia y España comparten el contexto geográfico europeo y pertenecen a la tradición religiosa cristiana; además, el serbio y el español pertenecen a la familia de las lenguas indoeuropeas.

En segundo lugar, el análisis ha demostrado que las ideas básicas de la muerte a nivel metafísico en las culturas y los idioma serbios y españoles son las siguientes: a) la existencia del alma / dualismo del alma y el cuerpo, b) la existencia del juicio final (día del juicio final) - el dualismo del mundo / la existencia del paraíso y el infierno, c) la inevitabilidad de la muerte - la predestinación de la vida / la existencia del destino, d) la incertidumbre de la muerte - la fecha y el lugar de la muerte son inciertos, e) la inmortalidad del alma / la vida (eterna) después de la muerte - morir es vivir eternamente. En conclusión, en los refranes han permanecido depositados diferentes estratos de creencias: se entrelazan tanto las visiones cristianas del fenómeno de la muerte como las precristianas. 


\section{FUENTES}

Correas, Gonzalo. Vocabulario de refranes y frases proverbiales. Madrid: Editorial Castalia, 2000 [1627]. Impreso.

Etxabe, Regino. Diccionario de refranes comentado. Madrid: Ediciones de la Torre, 2012. Impreso.

Junceda, Luis. Diccionario de refranes, dichos y proverbios. Madrid: Espasa, 2006. Impreso.

Kleut, Marija. Jednostavni oblici narodne književnosti. Novi Sad: Izdavački centar Matice srpske, 2010. Štampano.

Narodne poslovice. Biblioteka „Reč i misao“, Kolo VII, Knjiga 159.

Dušanka Perović (Urednica), Beograd: Rad, 1964. Štampano.

Panizo Rodríguez, Juliana. "La muerte en el refranero". Revista de Folklore, Núm. 210 (1998): 190-192. Impreso.

Refranero multilingüe. http://cvc. cervantes. es/lengua/refranero/

Default. aspx Web 15 Mar. 2019.

Šćepanović, Mihailo. Vukove srpske narodne poslovice s registrom ključnih reči, 2. izdanje. Beograd: Jasen, 2005. Štampano.

Tomić, Dejan. Srpske narodne pripovetke i poslovice. Novi Sad: Prometej, 1999. Štampano.

\section{BIBLIOGRAFÍA}

Berta, Peter. "Anthropological Perspective". Robert Kastenbaum (Ed.). Macmillan Encyclopedia of Death and Dying, Vol 1, New York: Macmillan Reference USA, 2003: 26-29. Print.

Boisclair, Regina A. "The Rituals for Dying, Death, and Bereavement among Roman Catholics and Eastern Orthodox Christians". L. Bregman (Ed.). Religion, death, and dying, Vol. 1: Perspectives on Dying and Death, Santa Barbara, California: ABC Clio, 2010: 41-61. Print.

Braun, Stiven F. Hrišćanstvo. Beograd: Čigoja štampa, 2000. Štampano.

Conzelus Moore, Calvin \& John B. Williamson. "The Universal Fear of Death and the Cultural Response". Clifton D. Bryant (Ed.). Handbook of death and dying, Vol. 1, Thousand Oaks, California: SAGE Publications, 2003: 3-13. Print.

Danesi, Marcel. "A Basic Course in Anthropological Linguistics". Studies in Linguistic and Cultural Anthropology, Vol. 2, Toronto: Canadian Scholars' Press Inc., 2004. Print.

Duranti, Alessandro. Linguistic anthropology. Cambridge: Cambridge University Press, 1997. Print. 
Duranti, Alessandro. "Linguistic Anthropology: History, Ideas, and Issues". Alessandro Duranti (Ed.). Linguistic Anthropology: A Reader. 2nd edition. Malden, MA: Wiley-Blackwell, 2009: 1-59. Print.

Erić, Ljubomir. Strah od smrti. Niš: Prosveta, 2001. Štampano.

Fernández, Eliecer Crespo. "The language of Death: Euphemism and Conceptual Metaphorization in Victorian Obituaries". Sky Journal of Linguistics, 19 (2006): 101-130. Print.

Georgijev, Ivana. „Tabui i eufemizmi kao primer kognitivnog kulturnog modela: SMRT u srpskom i španskom jeziku“. Nasleđe, časopis za književnost, jezik, umetnost i kulturu, Vol. XII, Br. 30 (2015): 221230. Štampano.

Georgijev, Ivana. „Metafore o smrti i umiranju u španskom i srpskom jeziku“. Godišnjak Filozofskog fakulteta u Novom Sadu, Vol. XLIII, Br. 2 (2018a): 181-194. Štampano.

Georgijev, Ivana. „Etnolingvistički pristup temi smrti u srpskim i španskim paremijama". Trabajo presentado en la conferencia internacional Jezici i kulture u vremenu i prostoru 8 [17.11.2018] en la Facultad de Filosofía y Letras de Novi Sad, 2018b. Štampano.

Kastenbaum, Robert. "Immortality". Robert Kastenbaum (Ed.). Macmillan Encyclopedia of Death and Dying, Vol 1, New York: Macmillan Reference USA, 2003: 456-461. Print.

Kearl, Michael C. Endings. A Sociology of Death and Dying. New York, Oxford: Oxford University Press, 1989. Print.

Krešić, Andrija. Filozofija religije. Beograd: Filip Višnjić, 2006. Štampano. McGuckin, J. A. "Hell". Robert Kastenbaum (Ed.). Macmillan Encyclopedia of Death and Dying, Vol 1, New York: Macmillan Reference USA, 2003: 404-408. Print.

Pascual López, Xavier. "El refrán como producto lingüístico-cultural". Janusz Pawlik \& Jerzy Szałek (Eds.). Lingüística española en Polonia: Líneas de investigación, 2014: 169-178. Impreso.

Pejović, Andjelka. „Paremije kao deo etnolingvističkog nasleđa”. Glasnik Etnografskog instituta SANU, Vol. 62, Br. 2 (2014): 201-214. Štampano.

Popović, Marko. „Srednjovekovna epoha“. Marko Popović et al. (Urednici). Istorija privatnog života u Srba: od srednjeg veka do savremenog doba, Beograd: Clio, 2011: 19-170. Štampano.

Tadić, Ljubomir. Zagonetka smrti: smrt kao tema religije i filozofije. Beograd: Filip Višnjić, 2003. Štampano.

Zečević, Slobodan. Kult mrtvih kod Srba. Beograd: Službeni glasnik, 2007. Štampano.

Zečević, Slobodan. Kult mrtvih kod Srba. Beograd: Vuk Karadžić, Etnografski muzej, 1982. Štampano. 


\title{
DEATH AS A METAPHYSICAL PHENOMENON IN SERBIAN AND SPANISH PROVERBS AND SAYING: ETHNOLINGUISTIC APPROACH
}

\begin{abstract}
Summary
The phenomenon of death, as an inseparable part of life, has not failed to attract attention from the most remote times of humanity. For this reason, death as a phenomenon has been an unavoidable topic in anthropological, ethnological and cultural research. Due to its universality, we have decided to analyze the concept of death as a metaphysical phenomenon in Serbian and Spanish proverbs and sayings. The ethnolinguistic approach offers us the possibility to investigate social, historical and cultural background of the proverbs. Representing an important part of Serbian and Spanish oral heritage and folklore, proverbs and sayings describe beliefs of these two societies, mainly on the collective level of attitudes and reflections on a particular subject (in this case, death). The objective of this paper is to point out similarities and differences between these two language communities and cultures, in order to confirm the ethnolinguistic nature of proverbs, as well as to show the importance of their comparative study.

Keywords: ethnolinguistics, proverb and saying, death, Serbian language, Spanish language.
\end{abstract}

